\title{
Predictive Effect of Parenting Practices on Social Interaction of Primary School Pupils in ljebu North Local Government Area of Ogun State, Nigeria
}

\author{
Shoaga, Opeyemi Ph.D \\ Department of Educational Foundations and Counselling, Faculty of Education, \\ Olabisi Onabanjo University, Ago-Iwoye, Ogun State, Nigeria \\ shoagaopeyemi@gmail.com
}

\author{
Doi:10.5901/ajis.2015.v4n1p339
}

\begin{abstract}
This study examined the predictive effect of Parenting Practices on Social Interaction of Pupils with a view to suggesting ways of improving students' social interaction and performance in school. For the purpose of this research work, descriptive research design of ex-post facto type was adopted. The sample for this study comprised of two hundred and fifty (250) respondents that were randomly selected from five primary schools. Fifty respondents (50) respondents were randomly selected from each of the five primary schools. Alabama Parenting questionnaire and social Interaction scale were used in gathering the needed information. Pearson Product Moment Correlation (PPMC) and Multiple Regression Analysis were used to analyse the data collected. The results of the findings were as follows: There was a significant contribution of Parenting Practices on students' Social Interaction and there was a relative effect of Positive Parenting on Social Interaction of Pupils. Based on the findings of this study, it is recommended that Educators should realize how essential it is to ensure the appropriate parenting style which in turn would result in a better students' social interaction in school. The awareness of the importance of the impact of parenting practices will also assist the educators, counselors, and psychologist to understand to what extent the role played by home could help them to manage students' performance in academic life.
\end{abstract}

Keywords: Social Interaction, Parenting Practices, Discipline, Competence and Pupils

\section{Introduction}

In the past two decades children's social interaction problems have received considerable attention from researchers in Nigeria. Nowadays it is widely accepted that learning is a product of social interaction (Stard, 2002). Children are not born with social skills, the ability for children to make friends and learn social skills starts with the first few years of life. The bonds of healthy attachment in the parent-child relationship set the stage for trust, empathy and other friendship skills for future social interaction with peers (Kelly, 2009).

The family is a socio-cultural- economic arrangement that exerts significant influence on children's social interaction and development of their character (Ogunkola, 1999). Ignorance on the part of parents may lead to unwanted damaging effects on pupil's growth and thereafter may create misbehaviour or interaction problems for the pupils. The term parenting practices refers to behaviours defined by specific content and socialisation goals (Darling \& Steinberg, 1993). It is a generalized term used to refer to characteristic ways of handling or dealing with one's children (Judy 2000). How parents bring up their children and how parental characteristics are infused into child personality are questions that continue to inspire research (Kail and Cavanaugh 2000). Some parenting practices are claimed to affect the likelihood of children behaving in the ways that lead to school success as well as promoting children's 'cognitive ability' and 'thinking skills' (Hoover-Dempsey and Sandler 1995).

Accordingly, research in child development psychology has demonstrated that not only the total amount of time but also the type of activities parents engage in are important determinants of a child's well being (Pleck1996). To this extent, some childcare practices are more vital in enhancing children's success in school. Variations in specific parenting behaviours could be informative in understanding the differential transmission of parental advantages to children.

Occasionally, one still hears what used to be a popular catch phrase: 'There are no problem children, only problem parents', this statement refers, in part, to an explanation of why children fail to adapt to society's norms. Most parents complain about their children and they often become worried and tensed about their children's incompetencies and inabilities. The way in which parents bring up their children surely influences their overall development. If children are to develop positive aspects of their personality, then, parents need to look into the different aspects of parenting (Durkin 
1995 as cited by Sonia \& Amar 2012).

Parental warmth, Parental discipline and cogntive stimulation play important roles in the development of social competence in children. These forms of positive emotional support has been linked with children's cooperation, regulations of emotions, prosocial behaviours and peer acceptance in children from infancy through adolescence (MillerLoncar, Landry, Smith, and Swank, 2000; Hart, Dewolf, Wozniak and Burts, 1992 \& Marcon, 1999) Studies on the effects of attitudinal styles of parenting, parental stress, and parental efficacy are common but few measures tap both the positive and negative dimensions of parenting practices on social competence and interaction. Knowledge about Parenting Practices, values, attitudes, and behaviours among many tribes in Nigeria particularly in ljebu Area are limited. Thus there is the need to understand child-rearing practices among parents in Nigeria.Therefore, this study is out to examine how parenting practices might influence children's social interaction, with a view to suggesting ways of improving students' social interaction and performance in school. This study will also provide some bases on which recommendation can be made for improving students' social skills.

\subsection{Objective of the Study}

The objective of this study is to look into effect of parenting practices as it predicts the social interactions of Primary School pupils

\section{Literature Review}

This section looks into the various variables identified in this study which are parenting practices and social interaction.

\subsection{Parenting Practices}

Parenting Practices are behaviours exhibited by parents in order to socialize their children (2005). Parenting is an important task of individual families and it is equally challenging. Parenting as a duty has some accompanying features such as nurturing the child, providing safety and ensuring conducive learning environment for the child.

Parenting practices has significant effect on the child. It influences the child's social, physical and cognitive development. It could either positively or negatively affect the child. These practices elicit specific and definite responses from the child. Many parents are unaware of the fact that whatever parenting style or practice they adopt have implication for the all round development of the child particularly their social development.

When children are deficient in their social attitudes, it tells on other areas of development such as cognitive development, interaction with peers, academic achievement and so on.

In view of this, Maccoby and Martin (1983) identified four parenting styles;

\subsubsection{Authoritarian Parenting Practice:}

Authoritarian parents tend to set high standards and guidelines, and obedience is required. They rely on power assertion, rather than reason. In this style of parenting, children are expected to follow the strict rules established by the parents. Failure to follow such rules usually results in punishment. Authoritarian parents fail to explain the reasoning behind these rules and they are not responsive to their children. According to Baumrind, these parents "are obedienceand status-oriented, and expect their orders to be obeyed without explanation" (1991).

\subsubsection{Authoritative Parenting Practice:}

Authoritative parents offer a relatively equal balance of discipline and nurturing behaviours. They are responsive to their children's needs and willing to listen to questions. Research has linked an authoritative parenting practice to children's cognitive and social competence (Lamborn et al., 1991; Clawson \& Robila, 2001). Like authoritarian parents, the authoritative parents establish rules and guidelines that their children are expected to follow. However, this parenting style is much more democratic. When children fail to meet the expectations, these parents nurture and forgive rather than punish. Baumrind suggests that these parents "monitor and impart clear standards for their children's conduct. They are assertive, but not intrusive and restrictive. Their disciplinary methods are supportive, rather than punitive. They want their children to be assertive as well as socially responsible, and self-regulated as well as cooperative" (1991). 


\subsubsection{Permissive Parenting Practice:}

Permissive parents, sometimes referred to as indulgent parents, have very few demands to make of their children. These parents rarely discipline their children because they have relatively low self-control. They are extremely lax in regards to disciplining their children and they do not set appropriate limits on their child's behaviours (Baumrind, 1966). Lamborn et al. (1991) found that adolescents from permissive homes scored the lowest on the majority of adjustment indices. Furthermore, Baumrind (1971) found that permissive parents tended to have children who were rebellious, impulsive and low in achievement. They are generally nurturing and communicative with their children, often taking on the status of a friend more than that of a parent.

\subsubsection{Uninvolved Parenting Practices:}

They are often called neglectful, indifferent or dismissive parents. This is due to their lack of emotional involvement and supervision of their children. They are both unresponsive and undemanding towards the child. They are not usually involved in their children's life, but will provide basic needs for such children. In most cases, these children tend to lack self-control, have low self-esteem and are less competent than their peers.

\subsection{Social Interaction}

Social interaction is seen as "any situation involving two or more people in which the behaviour of each person is in response to the behaviour of the person" (Wheeler and Suls, 2007). According to Cardwell, Clark and Meldrum (2004) as cited by Azeez and Azeez (2009), Social interaction skills is the ability to establish and maintain mutually satisfying emotional closeness, intimacy and by giving and receiving attention. It is an encounter with another person or with other people which endures through time. It is characterised by many features, such as expectations, responsibilties, rules, roles, giving and taking. Studies have shown that people with strong social interaction tend to be happier and healthier (De Paula, 2005). In addition, social interaction provides the social support needed for each individual's Physical and Mental well-being (Tschan, Semmer \& Inversin, 2004).

\section{Hypotheses}

(1) There is no significant composite effect of Parenting Practices (Positive Parenting, Inconsistent Discipline and Poor Supervision) on Social Interaction of Pupils.

(2) There is no significant relative effect of Parenting Practices (Positive Parenting, Inconsistent Discipline and Poor Supervision) on Social Interaction of Pupils.

\section{Research Methods}

\subsection{Research Design}

For the purpose of this research work, descriptive research design of ex-post facto type was adopted. This is appropriate because all the variables would not be manipulated but would be described as they exist. This design has been found appropriate as no manipulation of independent variable was undertaken.

\subsection{Population and Sample}

The population of this study comprised of all the Primary school students in ljebu North local government area of Ogun state. The sample for this study comprised of two hundred and fifty (250) respondents that were randomly selected from Five Primary secondary schools. Fifty respondents (50) respondents were randomly selected from each of the five schools. A simple random sampling technique was used to select the five schools. The resulting sample consisted of 124 (51\%) Male Pupils (mean age $=10.56$; standard deviation= 1.43 ) and $119(49 \%)$ Female Pupils (mean age $=10.20$; standard deviation=1.47) Total (mean age $=10.38$; standard deviation $=1.45$ ) The average Age of the respondents was 10.38 years. 


\subsection{Research Instrument}

The following two instruments were used in this study: The instruments are:-

Alabama Parenting Questionnaire (APC-9 Short Form): This was developed by Frank, Daniel, Mark and Nadine (2006) in order to assess the parenting practices of Pupils. Three broad dimensions were assessed: Positive Parenting, Inconsistent Discipline and Poor Supervision. The short scale was then validated in independent community samples using confirmatory factor analysis and measures of disruptive 342 behavioural disorders in children. The instrument is a self report questionnaire with a five point likert scale response format. This scale consists of 9 items which is scored by reverse-scoring the negatively worded items and then summing the response values in each section. The range of possible scores on the three-item scales is 0 to 15. Its' cronbach alpha of the subscales were 0.89 (Positive Parenting), 0.90 (Inconsistent Discipline) and 0.76 (Poor Supervision),

Social Interaction Scale; Positive relations with others subscale of Ryff's Psychological well-being scale was adapted. This is a 9-item scale developed by Ryff and Keyes (1995). The instrument is a questionnaire with a six point scale response format. Its' cronbach alpha ranged from 0.87 to 0.91

\subsection{Administration of the Instrument}

The scales were administered by the researcher to the respondents in the selected working place and it was collected after completing the filling immediately.

\subsection{Method of Data Analysis}

The statistical method used in analyzing the hypotheses in this study was Pearson Product Moment Correlation (PPMC) and Multiple Regression Analysis.

\section{Results}

\subsection{Preliminary Results}

The results of the study are presented in the tables below:

Table 1: Descriptive statistics and Correlation Matrix of Emotional intelligence and Work-family conflict on organizational citizenship behaviour of female teachers

\begin{tabular}{llcccccc}
\hline & & Mean & Standard Deviation & 1 & 2 & 3 & 4 \\
\hline 1 & Positive Parenting & 8.843 & 2.245 & 1 & -.036 & $-.129^{*}$ & $.176^{\star \star}$ \\
2 & Inconsistent discipline & 8.683 & 3.084 & & 1 & $.527^{\star *}$ & -.042 \\
3 & Poor supervision & 7.094 & 1.768 & & & 1 & -.093 \\
4 & Social Interaction & 19.214 & 7.202 & & & 1 \\
\hline
\end{tabular}

* Correlation is significant at the 0.05 level (2-tailed).

The results in Table 1 revealed that significant correlation existed between Positive Parenting and social interaction ( $r(243)$ $=.176 ; P<.05)$ while no significant correlation existed between Inconsistent Discipline and social interaction $(r(243)=.042$; $\mathrm{P}>$.05) and no correlation also existed between Poor supervision and social interaction ( $\mathrm{r}(243)=.093$; $\mathrm{P}>.05$ ) respectively.

\subsection{Hypothesis One}

There is no significant composite effect of Parenting Practices (Positive Parenting, Inconsistent Discipline and Poor Supervision) on Social Interaction of Pupils. 
Table 1: Summary of Multiple Regression analysis of the effect of Parenting Practices (Positive Parenting, Inconsistent Discipline and Poor Supervision) on Social Interaction of Pupils.

\begin{tabular}{|c|c|c|c|c|c|c|}
\hline \multicolumn{2}{|l|}{ REGRESSION } & \multicolumn{5}{|l|}{ ANOVA } \\
\hline Model & Source & Sum Of Squares & Df & Mean Square & $\mathrm{F}$ & Sig \\
\hline$=.190^{a}$ & Regression & 452.369 & 3 & 150.790 & 2.978 & $.032^{a}$ \\
\hline$=.036$ & Residual & 12102.504 & 239 & 50.638 & & \\
\hline Adj. $R^{2}=.024$ & Total & 12554.872 & 242 & & & \\
\hline
\end{tabular}

The result in Table 1 indicated that Parenting Practices significantly predicted the social interaction of students $(R=.190$; $\left.\mathrm{R}^{2}=.036 ; \mathrm{F}_{(3,242)}=2.978 ; \mathrm{P}<.05\right)$. This showed that child rearing accounted for $3.6 \%$ of the variance in the social interaction of students. The null Hypothesis which states that there is no significant contribution of Parenting Practices on Social Interaction was hereby rejected.

\subsection{Hypothesis Two}

There is no significant relative effect of Parenting Practices (Positive Parenting, Inconsistent Discipline and Poor Supervision) on Social Interaction of Pupils.

Table 2: Beta coefficients and t Ratio for relative effect of Parenting Practices (Positive Parenting, Inconsistent Discipline and Poor Supervision) on Social Interaction of Pupils.

\begin{tabular}{|ll|r|r|r|r|r|}
\hline \multirow{2}{*}{ Model } & \multicolumn{2}{|c|}{$\begin{array}{c}\text { Unstandardized } \\
\text { Coefficients }\end{array}$} & $\begin{array}{c}\text { Standardized } \\
\text { Coefficients }\end{array}$ & \\
\cline { 2 - 5 } & \multicolumn{1}{|c|}{$\mathrm{B}$} & Std. Error & \multicolumn{1}{|c|}{ Beta } & \multicolumn{1}{c|}{ S } & \multicolumn{1}{c|}{ Sig. } \\
\hline 1 & (Constant) & 16.538 & 2.810 & & 5.885 & .000 \\
& Positive Parenting & .535 & .206 & .167 & 2.602 & .010 \\
& InconsistentDiscipline & .005 & .175 & .002 & .030 & .976 \\
& Poor Supervision & -.296 & .307 & -.073 & -.964 & .336 \\
\hline
\end{tabular}

a. Dependent Variable: Social interaction

The results in Table 2 revealed that only one predictor variable was a good predictor of Social Interaction. Positive Parenting was the most potent predictor variable $(\beta=.535 ; t=2.602 ; P<.05)$ while Inconsistent Discipline $(\beta=.005 ; t=$ $0.30 ; P>.05)$ and Poor supervision $(\beta=.320 ; t=6.201 ; P>.05)$ were not predictors of Social interaction. This implies that there is relative effect of Positive Parenting on Social Interaction of Pupils.

\section{Discussion of Findings}

This study examined the predictive effect of parenting practices on social interaction of pupils in primary schools. The first hypothesis which stated that there is no significant contribution of Parenting Practices on students' Social Interaction was by the findings of this study was rejected. The results according to Table 1 revealed that there was a significant contribution of Parenting Practices on students' Social Interaction. This result corroborated the Findings of Miller-Loncar, Landry, Smith, and Swank (2000); Hart, Dewolf, Wozniak and Burts, (1992) and Marcon (1999) who revealed from their studies that Parental warmth, Parental discipline and cogntiive stimulation played important roles in the development of social competence in children.

The second hypothesis stated that there was no significant relative effect of Parenting Practices (Positive Parenting, Inconsistent Discipline and Poor Supervision) on Social Interaction of Pupils. The results according to Table 3 revealed that there was a significant contribution of Positive Parenting Practices on Pupils' Social Interaction. The reason for the prediction of Positive parenting on Social interaction could be because it promotes social qualities such as sharing techniques, apologetic gestures, forgiveness, patience, care, self control, kindness, deliberation, even maturity and other friendship skills. This corroborated the findings of Cassel \& Bernstein, (2006)who revealed that when parenting practices do not include clear expectations, or fail to provide proper supervision, children are at risk for developing behavioural problems. Poor parental supervision in many cases begins at early childhood; however, the consequences of this parenting style might not become obvious until the child reaches adolescence. Inconsistency among the parents (sometimes allowing particular behavior and sometimes punishing it) may also contribute to an individual's criminal potential. Parents who tend not to explain to children why they are being punished make it difficult for the child to identify 
the behavior that he was being punished for. Even though the consequences of lack of supervision might have different effect on girls and boys, generally, lack of supervision and attention has an enormous impact on a child and a child's criminal potential.

\section{Conclusion and Recommendations}

Social interaction can also be seen as a process of communicating with other selves. It can be concluded from the result of this study that there was a significant contribution of Parenting Practices on students' Social Interaction and there was relative effect of Positive Parenting on Social Interaction of Pupils. Based on the findings of this study, it is recommended that Educators should realize how essential it is to ensure the appropriate parenting style which in turn would result in a better students' social interaction in school. The awareness of the importance of the impact of Parenting Practices will also assist the educators, counselors, and psychologist to understand to what extent the role played by home could help them to manage students' performance in academic life. By having knowledge and understanding on this area, it could help many parties, such as educators, counselors, and psychologist to design and develop proper intervention program to enhancing social support among students. Therefore, enhancing knowledge and strategies in promoting the role of family and friends as agents of social interaction among students may help to increase their academic achievement. It is recommended that additional knowledge about parental and peer attachments may be gained by obtaining ratings from the parents and friends on various aspects of their relationships with their children and friends.

In order to confirm the relationship and contribution model of Parenting Practices and social interaction, future research should be expanded to include participants from a wider variety of age groups, socioeconomic strata, ethnic or cultural groups, and types of school settings (e.g., rural or urban locations). Results from a wider variety of students will allow greater generalizability of the results. Students from community schools, in particular, may exhibit different patterns of interactions of the variables within the model.

\section{References}

Azeez, R. O \& Azeez, A. A. (2009)Achievement striving, Self-efficacy and Social Interaction among Local Government staff in Ogun East Senatorial District of Nigeria. African Journal of Research in personnel and counselling Pscychology, 1(2), 1-7.

Baumrind, D. (1966) Effect of authoritative parental control on child behaviour, Child Development, 37, 887-907.

Baumrind, D. (1971) Current patterns of parental authority, Developmental Psychology Monographs, 4(2), 1-103.

Baumrind, D. (1991). The influence of parenting style on adolescent competence and substance use. Journal of Early Adolescence, 11(1), 56-95.

Cardwell, M., Clark, L. \& Meldrum, C. (2004). Psychology (3rd Ed.). Harper Collins Publishers.

Cassel, E, \& Bernstein, D.A. (2006) Criminal behaviour. London: Psychology Press.

Clawson, M. A. \& Robila, M. (2001) Relations between parenting style and children's play behaviour: issues in education [abstract], Journal of Early Education and Family Review, 8(3), 13-19.

Darling, N., \& Steinberg, L. (1993). Parenting style as context: An integrative model. Psychological Bulletin, 113, 487-496.

De Paula, A. (2005).Inference in a synchronisation game with social Interactions. Princeton University, Mimeo.

Durkin, K. (1995). Developmental Social Psychology: From Infancy to Old Age. Cambridge: Blackwell Publishers Inc.

Hart, C., Dewolf, D., Wozniak, P. \& Burts, D. (1992). Maternal and Paternal disciplinary styles: Relations with preschoolers' playground behavioural orientations and Peer status. Child development, 63, 879-892.

Hoover-Dempsey, K.V. \& H.M. Sandler. (1995). Parental Involvement in Children's Education: Why Does It Make a Difference? Teachers College Record 97(2):310-331.

Judy, P. (2000). The New Oxford Dictionary of English. New York: Oxford University Press.

Kail, V. R. \& Cavanaugh, C. J. (2000). Human Development: A Lifespan View. Belmont: Wadsworth.

Kelly Pfeiffer April 22, 2009 " healthy attachment helps children make friends"

Lamborn, S. D., Mounts, N. S., Steinberg, L. \& Dornbush, S. M. (1991) Patterns of competence and adjustment among adolescents from authoritative, authoritarian, indulgent, and neglectful families, Child Development, 62(5), 1049-1065.

Maccoby, E. E., \& Martin, J. A. (1983). Socialization in the context of the family: Parent-child interaction. In P. H. Mussen \& E. M. Hetherington, Handbook of child psychology: Vol. 4. Socialization, personality, and social development (4th ed.). New York: Wiley.

Marcon, R. (1999). Differential impact of preschool models on development and early learning of inner-city children: A three cohort study. Development Psychology Monographs, 35(2),358-375.

Miller-Loncar, C., Landry, S., Smith, K., \& Swank, P. (2000). The influence of complexity of maternal thoughts on sensitive parenting and children's social responsiveness. Journal of applied development Psychology, 21, 335-356.

Ogunkola, B. J. (1999): Interaction Patterns in Primary School Science Classrooms in ljebu-Ode. African Journal of Educational Research (5)1, 51-61. 
Pleck, J.H. \& B. Masciadrelli. 2004. "Paternal involvement: Levels, Sources, and Consequences (Pp. 227-271). In M.E. Lamb (4th ed.) "The Role of the Father in Child Development". New York: Wiley.

Ryff, C. D. \& C. L. Keyes. (1995). The Structure of Psychological Well-Being Revisited. Journal of Personality Social Psychology 69(4):719-27.

Sonia, G. \& Amar, R. (2012). Factors of Child-rearing Practices: A Qualitative Analysis. Journal of Psychology, 3(2): 99-105.

Spera, Christopher (2005). A review of the relationship among parenting practices, parenting styles and adolescent school achievement. Educational Psychology Review 17(2):125-146

Tschan, F., Semmer, N. K. \& Inversin, L. (2004). Work-related and Private Social Interactions at work. Social Indicators Research, 67, 145-182.

Wei, M. F., Heppner, P. P., \& Mallinckrodt, B. (2003). Perceived coping as a mediator between attachment and psychological distress: $A$ structural equation modeling approach. Journal of Counseling Psychology, 50(4), 438-447.

Wheeler, L. \& Suls, J. (2007). Assimilation in Social comparison: Can we agree on what it is? International Review of Social Psychology, 20(1) 31-51. 
